\title{
Antifungal Susceptibility Patterns of Candida Species Recovered from Endotracheal Tube in an Intensive Care Unit
}

\author{
Elham Baghdadi, ${ }^{1}$ Sadegh Khodavaisy, ${ }^{2,3}$ Sassan Rezaie, ${ }^{3}$ Sara Abolghasem, ${ }^{4}$ \\ Neda Kiasat, ${ }^{5}$ Zahra Salehi, ${ }^{6}$ Somayeh Sharifynia, ${ }^{7}$ and Farzad Aala ${ }^{2}$ \\ ${ }^{1}$ Department of Microbiology, Faculty of Science, Islamic Azad University, Varamin-Pishva Branch, Tehran, Iran \\ ${ }^{2}$ Department of Medical Parasitology and Mycology, Kurdistan University of Medical Sciences, P.O. Box 14155-6446, Sanandaj, Iran \\ ${ }^{3}$ Division of Molecular Biology, Department of Medical Mycology and Parasitology, School of Public Health, \\ Tehran University of Medical Sciences, Tehran, Iran \\ ${ }^{4}$ Department of Microbiology, Faculty of Science, Islamic Azad University, North Tehran Branch, Tehran, Iran \\ ${ }^{5}$ Department of Medical Mycology, Jondishapour University of Medical Sciences, Ahvaz, Iran \\ ${ }^{6}$ Department of Medical Mycology, Tarbiat Modares University, Tehran, Iran \\ ${ }^{7}$ Clinical Tuberculosis and Epidemiology Research Center, National Research Institute of Tuberculosis and Lung Diseases (NRITLD), \\ Shahid Beheshti University of Medical Sciences, Tehran, Iran
}

Correspondence should be addressed to Farzad Aala; farzadaala@yahoo.com

Received 20 April 2016; Revised 11 June 2016; Accepted 15 June 2016

Academic Editor: Anastasia Kotanidou

Copyright (C) 2016 Elham Baghdadi et al. This is an open access article distributed under the Creative Commons Attribution License, which permits unrestricted use, distribution, and reproduction in any medium, provided the original work is properly cited.

\begin{abstract}
Aims. Biofilms formed by Candida species which associated with drastically enhanced resistance against most antimicrobial agents. The aim of this study was to identify and determine the antifungal susceptibility pattern of Candida species isolated from endotracheal tubes from ICU patients. Methods. One hundred forty ICU patients with tracheal tubes who were intubated and mechanically ventilated were surveyed for endotracheal tube biofilms. Samples were processed for quantitative microbial culture. Yeast isolates were identified to the species level based on morphological characteristics and their identity was confirmed by PCRRFLP. Antifungal susceptibility testing was determined according to CLSI document (M27-A3). Results. Ninety-five strains of Candida were obtained from endotracheal tubes of which C. albicans $(n=34 ; 35.7 \%)$ was the most frequently isolated species followed by other species which included C. glabrata $(n=24 ; 25.2 \%)$, C. parapsilosis $(n=16 ; 16.8 \%)$, C. tropicalis $(n=12 ; 12.6 \%)$, and $C . \operatorname{krusei}(n=9 ; 9.4 \%)$. The resulting $\mathrm{MIC}_{90}$ for all Candida species were in increasing order as follows: caspofungin $(0.5 \mu \mathrm{g} / \mathrm{mL})$; amphotericin B $(2 \mu \mathrm{g} / \mathrm{mL})$; voriconazole $(8.8 \mu \mathrm{g} / \mathrm{mL})$; itraconazole $(16 \mu \mathrm{g} / \mathrm{mL})$; and fluconazole $(64 \mu \mathrm{g} / \mathrm{mL})$. Conclusion. Candida species recovered from endotracheal tube are the most susceptible to caspofungin.
\end{abstract}

\section{Introduction}

Nosocomial infections are an important cause of mortality and increasing hospital costs [1]. The infection is usually transmitted to susceptible patients through infected medical staff and equipment by pathogenic organisms [2]. Biofilms are microbial communities embedded in biopolymer matrix on living or nonliving substrates [3]. According to the National Institutes of Health America, approximately $80 \%$ of hospital infections are associated with microbial biofilms [4]. Important microorganisms involved in microbial biofilm formation predominantly consist of many species of both fungal and bacterial. Among pathogenic fungi, Candida species are the most common cause of superficial and systemic disease [5]. Candida species can aggregate on medical devices such as venous and urinary catheters, dentures, and ocular implants by biofilms [3, 6, 7]. Candida biofilms can identify in individuals with certain circumstances, such as immunocompromised patients, HIV infected, cancerous, and organ transplant recipients. Ventilator-associated pneumonia is the most frequent intensive care unit (ICU) acquired infection among patients ventilated through tracheostomy or endotracheal 
intubation [8]. This topic can provide the conditions such as prolonged hospitalization and use of a variety of devices for colonization and creating biofilms by Candida species. Biofilms formed by these fungal organisms are associated with drastically enhanced resistance against most antifungal therapy $[8,9]$. Several studies show that antifungal agents, that is, amphotericin B, fluconazole, itraconazole, and ketoconazole, displayed less activity against Candida albicans biofilms formed on the PVC disk [10-12]. In addition, nonC. albicans have shown resistance to two new antifungal drugs (voriconazole and ravuconazole), but it seems that antibiofilm activity of amphotericin B lipid formulation and also echinocandins have existed [13]. Therefore the aim of the present study was to evaluate antifungal susceptibility testing of Candida spp. isolated from endotracheal tubes in ICU patients.

\section{Materials and Methods}

This study was carried out in the Intensive Care Unit of the Imam Khomeini and Golestan Hospitals, Ahvaz, during January-September 2015. One hundred forty ICU patients with tracheal tubes who were intubated and mechanically ventilated were surveyed for endotracheal tube biofilms. The length of hospitalization was at least two weeks prior to sampling. Collected endotracheal tubes of patients who had clinical manifestation of pneumonia including cough, purulent respiratory secretion, fever, and new or progressive infiltration of lung in CXR were placed in sealed sterile bottles and referred immediately to the laboratory for processing. From the central region of each endotracheal tube $1 \mathrm{~cm}$ section was cut and processed for quantitative microbial culture.

2.1. Morphological and Molecular Identification. The specimens were inoculated onto Sabouraud Dextrose Agar (SDA, Difco) supplemented with chloramphenicol and incubated at $37^{\circ} \mathrm{C}$ for two days. Primarily, yeast colonies were identified by conventional tools such as colony color on CHROMagar Candida medium (CHROMagar Company, Paris, France), germ tube tests in serum at $37^{\circ} \mathrm{C}$ for $2-3 \mathrm{~h}$, and microscopic morphology on cornmeal agar (Difco Laboratories, Detroit, Mich., USA) with $1 \%$ Tween 80 . Confirmation molecular approaches were adjusted. Genomic DNA was extracted, using the method of glass bead disruption, and the PCRRFLP method was performed as described previously [14].

2.2. Antifungal Susceptibility Testing. MICs (minimum inhibitory concentrations) of identified Candida isolates were determined according to recommendations stated in the Clinical and Laboratory Standards Institute (CLSI) M27-A3 document [15]. Amphotericin B (Sigma, St. Louis, MO, USA), fluconazole (Pfizer, Groton, CT, USA), itraconazole (Janssen Research Foundation, Beerse, Belgium), voriconazole (Pfizer, Groton, CT, USA), and caspofungin (Merck, Whitehouse Station, NJ, USA) were obtained as reagent-grade powders from the respective manufacturers for preparation of the CLSI microdilution trays. Inoculum was prepared by gently scraping the surface of the fungal colonies with a sterile cotton swab moistened with sterile physiological saline. Conidial suspensions were adjusted to transmission of $75 \%$ to $77 \%$ at $530 \mathrm{~nm}$ (approximate $1 \times 10^{6}-5 \times 10^{6} \mathrm{CFU} / \mathrm{mL}$ ). The inoculum suspensions, including mostly nongerminated conidia, were diluted 1:1000 in RPMI 1640 medium and the final inoculum in assay wells was between $0.5 \times 10^{3}$ and $5 \times$ $10^{3} \mathrm{CFU} / \mathrm{mL}$. The microdilution trays were incubated at $35^{\circ} \mathrm{C}$ for 24-48 h. MICs were determined visually by comparison of the growth in the wells containing the drug with the drugfree control. Candida parapsilosis (ATCC 22019) and Candida krusei (ATCC 6258) reference strains were for quality control.

\section{Results}

Out of one hundred forty ICU patients hospitalized, ninetyfive strains of Candida which were obtained from endotracheal tubes were studied. The positive specimens belonged to 67 male and 28 female hospitalized patients. The duration of being intubated had a median of 9 days and hospital stay duration average was $29 \pm 3.6$ days. The isolates were confirmed based on species level using PCR-RFLP of which C. albicans ( $n=34 ; 35.7 \%)$ was the most frequently isolated species, followed by C. glabrata ( $n=24 ; 25.2 \%$ ), C. parapsilosis $(n=16 ; 16.8 \%)$, C. tropicalis $(n=12$; $12.6 \%)$, and $C$. krusei $(n=9 ; 9.4 \%)$. Table 1 summarizes the results of in vitro antifungal susceptibility profiles (MIC range, geometric mean $\mathrm{MIC}, \mathrm{MIC}_{50}$, and $\mathrm{MIC}_{90}$ ) of several antifungal drugs against all Candida species. The resulting $\mathrm{MIC}_{50}$ for all Candida species were in increasing order as follows: caspofungin $(0.5 \mu \mathrm{g} / \mathrm{mL})$; amphotericin B $(1 \mu \mathrm{g} / \mathrm{mL})$; voriconazole $(0.25 \mu \mathrm{g} / \mathrm{mL})$; itraconazole $(0.75 \mu \mathrm{g} / \mathrm{mL})$; and fluconazole $(4 \mu \mathrm{g} / \mathrm{mL})$. Results showed the widest range and the highest MICs for fluconazole $(0.016-\geq 64 \mu \mathrm{g} / \mathrm{mL})$, voriconazole $(0.016-\geq 16 \mu \mathrm{g} / \mathrm{mL})$, and itraconazole $(0.016-$ $\geq 16 \mu \mathrm{g} / \mathrm{mL}$ ). Results revealed statistically significant differences when comparing the susceptibility of C. albicans and non-albicans Candida to fluconazole, voriconazole, and itraconazole $(P<0.05)$ with $C$. albicans being found to be the most susceptible to these antifungal agents. MIC results among all the isolates of Candida species showed that they were fully susceptible to caspofungin (Table 2).

\section{Discussion}

Candida is opportunistic pathogen which causes a lifethreatening infection with high rates of mortality especially in immunocompromised individuals [16]. The pathogenicity of Candida species is attributed to certain virulence factors, mostly production of biofilm $[17,18]$. Candida species are now recognized as major agents of hospital-acquired infection. Almost invariably, an implanted device such as an urinary catheter or endotracheal tube is associated with these infections [18]. Candida species can cause significant problems of medical settings as persistent and recurrent device related infections $[19,20]$. This properties also differed among different species of Candida $[17,21]$. In this study C. albicans $(35.7 \%)$ was the most common species obtained from endotracheal tube, compatible with other studies that mentioned that C. albicans is considered as major etiologic 
TABLE 1: In vitro susceptibilities of Candida spp. recovered from endotracheal tube to antifungal agents. MIC range, geometric mean, $\mathrm{MIC}_{50}$, and $\mathrm{MIC}_{90}$ values are expressed in $\mu \mathrm{g} / \mathrm{mL}$.

\begin{tabular}{|c|c|c|c|c|c|}
\hline Species $(n)$ & Antifungal agents & Ranges & $\mathrm{MIC}_{50}$ & $\mathrm{MIC}_{90}$ & GM \\
\hline \multirow{5}{*}{ Total Candida spp. (95) } & Amphotericin B & $0.062-4$ & 1 & 2 & 0.420 \\
\hline & Itraconazole & $0.016-\geq 16$ & 0.75 & 4 & 0.847 \\
\hline & Voriconazole & $0.016-\geq 16$ & 0.25 & 4 & 0.381 \\
\hline & Fluconazole & $0.016-\geq 64$ & 4 & 64 & 2.881 \\
\hline & Caspofungin & $0.008-2$ & 0.5 & 0.5 & 0.294 \\
\hline \multirow{5}{*}{ C. albicans (34) } & Amphotericin B & $0.062-2$ & 0.5 & 2 & 0.178 \\
\hline & Itraconazole & $0.016-\geq 16$ & 0.062 & 16 & 0.242 \\
\hline & Voriconazole & $0.016-\geq 16$ & 0.031 & 8 & 0.119 \\
\hline & Fluconazole & $0.016-\geq 64$ & 0.5 & 8 & 0.999 \\
\hline & Caspofungin & $0.008-0.5$ & 0.5 & 0.5 & 0.182 \\
\hline \multirow{5}{*}{ C. glabrata (24) } & Amphotericin B & $0.062-2$ & 1 & 2 & 0.706 \\
\hline & Itraconazole & $0.016-16$ & 8 & 16 & 3.121 \\
\hline & Voriconazole & $0.016-16$ & 0.5 & 16 & 0.684 \\
\hline & Fluconazole & $0.25-16$ & 16 & 64 & 5.941 \\
\hline & Caspofungin & $0.125-1$ & 0.5 & 0.75 & 0.390 \\
\hline \multirow{5}{*}{ C. parapsilosis (16) } & Amphotericin B & $0.016-1$ & 0.25 & 0.5 & 0.158 \\
\hline & Itraconazole & $0.016-0.5$ & 0.5 & 0.5 & 0.249 \\
\hline & Voriconazole & $0.016-0.5$ & 0.125 & 0.25 & 0.157 \\
\hline & Fluconazole & $0.125-4$ & 2 & 2 & 1 \\
\hline & Caspofungin & $0.125-0.5$ & 0.5 & 0.5 & 0.314 \\
\hline \multirow{5}{*}{ C. tropicalis (12) } & Amphotericin B & $1-4$ & 2 & 4 & 2 \\
\hline & Itraconazole & $1-\geq 64$ & 16 & 16 & 7.245 \\
\hline & Voriconazole & $0.125-4$ & 2 & 2 & 1 \\
\hline & Fluconazole & $4-\geq 64$ & 16 & - & 19.02 \\
\hline & Caspofungin & $0.008-2$ & 0.5 & 0.5 & 0.458 \\
\hline \multirow{5}{*}{ C. krusei (9) } & Amphotericin B & $0.062-2$ & 2 & - & 0.447 \\
\hline & Itraconazole & $0.031-8$ & 0.37 & - & 0.398 \\
\hline & Voriconazole & $0.125-16$ & 0.25 & - & 0.870 \\
\hline & Fluconazole & $0.016-4$ & 32 & - & 2.512 \\
\hline & Caspofungin & $0.008-2$ & 0.375 & - & 0.353 \\
\hline
\end{tabular}

GM: geometric mean.

agent in candidiasis $[16,17,20]$. Other studies reported that the ability of biofilm production in C. parapsilosis and $C$. glabrata was significantly less than C. albicans [17, 21]. Biofilm phenotype in non-C. albicans species is the cause of the survival and well adapted to colonization of tissues and indwelling devices [20]. This difference in our results probably is due to variety of biofilms formation among Candida species from different sources. Mahmoudabadi et al. showed a higher percentage C. albicans (41.7\%) which have recovered from blood samples in comparison with other sources [21]. In our investigation, other species of Candida included $C$. glabrata (25.2\%), C. parapsilosis (16.8\%), C. tropicalis (12.6\%), and C. krusei (9.4\%) obtained from endotracheal tubes. These data are in agreement with the findings of a previous study [22-25]. Also Shokohi et al., Richter et al., and Papon et al. mentioned C. glabrata as the most common non-C. albicans species in their investigation [24-27]. Deorukhkar et al.s study indicated $C$. tropicalis $(29.4 \%)$ as the major non-C. albicans species isolate followed by C. glabrata $(20.7 \%)$ that is incompatible with these studies $[28,29]$. The obtained antifungal susceptibility patterns indicated that $C$. albicans isolates were highly susceptible to caspofungin (100\%) (MIC $\leq 2 \mu \mathrm{g} / \mathrm{mL}$ ). These findings are in agreements with other studies that reported [30,31]. In this investigation $26.4 \%$ of $C$. albicans strains were resistant to fluconazole (MIC $\geq 64 \mu \mathrm{g} / \mathrm{mL}$ ), whereas other studies reported the rates of this resistance as $45.83 \%, 11.9 \%, 74.2 \%, 2.7 \%$, and $38.7 \%$, respectively [27, 32-35]. Studies by Shokohi et al., Al-Mamari et al., Aher et al., Awari, and Roy et al. indicated the resistance of C. albicans to itraconazole as 5.4\%, 10.3\%, 36.9\%, $35 \%$, and $19.3 \%$, respectively $[26,32,36,37]$. However, in our finding $35.2 \%$ of $C$. albicans strains were shown to be resistant to itraconazole MIC $\geq 1 \mu \mathrm{g} / \mathrm{mL}$. In our study $14.7 \%$ of C. albicans isolates were resistant to voriconazole (MIC 
TABLE 2: MIC interpretation of five antifungal drugs against Candida spp. recovered from endotracheal tube.

\begin{tabular}{|c|c|c|c|c|c|c|}
\hline \multicolumn{2}{|c|}{ Antifungal agents } & $\begin{array}{c}\text { C. albicans } \\
\begin{array}{c}n=34 \\
(\%)\end{array}\end{array}$ & $\begin{array}{c}\text { C. glabrata } \\
\begin{array}{c}n=24 \\
(\%)\end{array}\end{array}$ & $\begin{array}{c}\text { C. parapsilosis } \\
n=16 \\
(\%)\end{array}$ & $\begin{array}{c}\text { C. tropicalis } \\
\begin{array}{c}n=12 \\
(\%)\end{array}\end{array}$ & $\begin{array}{c}\text { C. krusei } \\
n=9 \\
(\%)\end{array}$ \\
\hline \multirow{2}{*}{ Amphotericin B } & S & $28(82.3)$ & $20(83.3)$ & $16(100)$ & $10(83.3)$ & $7(77.7)$ \\
\hline & $\mathrm{R}$ & $6(17.6)$ & $4(16.6)$ & - & $2(16.7)$ & $2(22.2)$ \\
\hline \multirow{3}{*}{ Itraconazole } & S & $20(58.8)$ & $12(50)$ & $6(37.5)$ & $4(33.3)$ & $3(33.3)$ \\
\hline & $\mathrm{DD}$ & $2(5.8)$ & $6(25)$ & $10(62.5)$ & - & $5(55.5)$ \\
\hline & $\mathrm{R}$ & $12(35.2)$ & $6(25)$ & - & $8(66.6)$ & $1(11.1)$ \\
\hline \multirow{3}{*}{ Voriconazole } & $S$ & $27(79.4)$ & $11(45.8)$ & $12(75)$ & $4(33.3)$ & $6(66.6)$ \\
\hline & $\mathrm{DD}$ & $2(5.8)$ & $5(20.8)$ & $4(25)$ & $3(25)$ & $2(22.2)$ \\
\hline & $\mathrm{R}$ & $5(14.7)$ & $8(33.3)$ & - & $5(41.6)$ & $1(11.1)$ \\
\hline \multirow{3}{*}{ Fluconazole } & $S$ & $22(64.7)$ & $3(12.5)$ & $14(87.5)$ & $3(25)$ & $5(55.5)$ \\
\hline & $\mathrm{DD}$ & $3(8.8)$ & $2(8.3)$ & $2(12.5)$ & $4(33.3)$ & $2(22.2)$ \\
\hline & $\mathrm{R}$ & $9(26.4)$ & $19(79.1)$ & - & $5(41.6)$ & $2(22.2)$ \\
\hline \multirow{2}{*}{ Caspofungin } & $S$ & $34(100)$ & $24(100)$ & $16(100)$ & $12(100)$ & $9(100)$ \\
\hline & $\mathrm{R}$ & - & - & - & - & - \\
\hline
\end{tabular}

S: susceptible; R: resistance; DD: dose-dependent.

$\geq 1 \mu \mathrm{g} / \mathrm{mL}$ ) that was different from results of Zang et al. and Badiee and Alborzi's studies $[23,38]$. MIC range $(0.016-$ $\geq 16 \mu \mathrm{g} / \mathrm{mL})$ and $\mathrm{MIC}_{90}(8 \mu \mathrm{g} / \mathrm{mL})$ for voriconazole in present study were different from results by Zhang et al. and Badiee and Alborzi which reported MIC range and MIC90 as 0.0313$4 \mu \mathrm{g} / \mathrm{mL}$ and $0.25 \mu \mathrm{g} / \mathrm{mL}$ and $0.003-16 \mu \mathrm{g} / \mathrm{mL}$ and $4 \mu \mathrm{g} / \mathrm{mL}$, respectively $[23,38]$. In addition, $17.6 \%$ of $C$. albicans isolates in our study were indicated to be resistant to amphotericin $\mathrm{B}$ MIC $\geq 2 \mu \mathrm{g} / \mathrm{mL}$. The result was to some extent similar to the result reported by of Aher et al. (13.8\%) and differs from results by Njunda et al. (54.4\%), Awari et al. (7.5\%), and Zhang et al. (1.1\%) [26, 33, 35, 37-39]. MIC range (0.062$2 \mu \mathrm{g} / \mathrm{mL})$ and $\mathrm{MIC}_{90}(2 \mu \mathrm{g} / \mathrm{mL})$ for amphotericin B in present study differ from the data reported by Bosco-Borgeat et al. which reported MIC Range and $\mathrm{MIC}_{90}$ as $0.13-1 \mu \mathrm{g} / \mathrm{mL}$ and $0.5 \mu \mathrm{g} / \mathrm{mL}$, respectively [39]. Our data indicated that $79.1 \%$ of C. glabrata were resistance to itraconazole. These data are in disagreement with the rate of itraconazole resistance C. glabrata in studies by Shokohi et al. (12.5\%), Haddadi et al. (21\%), and Deorukhkar et al. (46.2\%) [27, 29, 40]. Also Aher reported $46.4 \%$ and $40 \%$ resistance to fluconazole and itraconazole, respectively; these mentioned rates differ from the results of our investigation [26]. Our study has shown that fluconazole $\mathrm{MIC}_{90}$ values $(8,64$, and $2 \mu \mathrm{g} / \mathrm{mL})$, itraconazole $(16,16$, and $0.5 \mu \mathrm{g} / \mathrm{mL})$, and voriconazole $(8,16$, and 0.25) against C. albicans, C. glabrata, and C. parapsilosis, respectively, according to study by Badiee and Alborzi in regard to fluconazole rates are lower $(16,128$, and 4$)$ and itraconazole and voriconazole have higher amount $(2,16$, and 0.25 and 4, 3, and 0.033), respectively [23]. In fact, $\mathrm{MIC}_{90}$ in C. glabrata as the main non-Candida albicans to fluconazole, itraconazole, and voriconazole was higher than C. albicans and C. parapsilosis. $\mathrm{MIC}_{90}$ fluconazole, itraconazole, and voriconazole for C. glabrata in our investigation were 64, 16, and 16. Long term fluconazole and itraconazole prophylaxis were accompanied with reduction in sensitivity to these agents and recently C. glabrata known as naturally less susceptible to azoles compared to other Candida species $[35,41,42]$. Our study has shown that amphotericin B and caspofungin $\mathrm{MIC}_{90}$ values were 2, 2, and $0.5 \mu \mathrm{g} / \mathrm{mL}$ and $0.5,0.75$, and $0.5 \mu \mathrm{g} / \mathrm{mL}$ against C. albicans, C. glabrata, and C. parapsilosis, respectively. However in other studies $\mathrm{MIC}_{90}$ values of amphotericin B were lower $(0.25,0.5$, and $0.25 \mu \mathrm{g} / \mathrm{mL}$ ) [23]. In present study $87.5 \%, 37.5 \%$, and $75 \%$ of C. parapsilosis strains were susceptible to fluconazole, itraconazole, and voriconazole, respectively. This result is similar to that by Shokohi et al. who found no resistance species among them. Badiee et al. obtained 6.9\% and 3.5\% resistance to fluconazole and itraconazole, respectively. In addition they find no voriconazole resistance C. parapsilosis among them. In addition Zhang et al's findings show $15.4 \%$ resistance to fluconazole; however there was no resistance to itraconazol and voriconazole $[23,27,38]$. In our study we find that $41.6 \%, 66.6 \%$, and $41.6 \%$ of C. tropicalis were resistant to fluconazole, itraconazole, and voriconazole, respectively. In contrast, Shokohi et al. did not find resistance species in their study. Also Zhang et al. and Aher et al. obtained $10.7 \%$ and $4.8 \%$ and $52 \%$ and $56 \%$ of isolates which were resistant to fluconazole and itraconazole, respectively [26, 27, 38]. However C. tropicalis isolates were highly susceptible to caspofungin and amphotericin B (100\%, 83.3\%). Therefore these antifungals seem to be the most active drug for candidiasis treatment. In our study $\mathrm{MIC}_{90}$ of fluconazole, itraconazole, and voriconazole for C. parapsilosis were 2, 0.5 , and $0.25 \mu \mathrm{g} / \mathrm{mL}$ whereas Zhang et al., Tay et al., and Bonfietti et al. obtained 2, 0.062, and $0.25 \mu \mathrm{g} / \mathrm{mL}, 4,0.19$, and $0.047 \mu \mathrm{g} / \mathrm{mL}, 2,0.06$, and $0.03 \mu \mathrm{g} / \mathrm{mL}$, respectively, as $\mathrm{MIC}_{90}$ to mention antifungal drugs $[38,43,44]$. Our results indicated that $C$. parapsilosis isolates from endotracheal tube were highly susceptible to caspofungin and amphotericin B; this data also shows that the concentration of $0.5 \mu \mathrm{g} / \mathrm{mL}$ of this medicine is able to inhibit $90 \%$ of mentioned isolates. 


\section{Conclusion}

Knowledge of Candida species distribution and antifungal resistance pattern of them plays an important role in appropriate therapy. Our results suggest that Candida species recovered from endotracheal tube are the most susceptible to caspofungin, followed by amphotericin B, voriconazole, itraconazole, and fluconazole.

\section{Competing Interests}

The authors declare no competing interests.

\section{Acknowledgments}

The authors are grateful to Dr. Hamid Badali, Mohammad Reza Safari, and Azar Berahmeh for their help in part of the analysis. The authors wish to thank the staff of Imam Khomeini and Golestan Hospitals for help in technical assistance to sampling.

\section{References}

[1] R. P. Wenzel, "Nosocomial candidemia: risk factors and attributable mortality," Clinical Infectious Diseases, vol. 20, no. 6, pp. 1531-1534, 1995.

[2] S. Khodavaisy, M. Nabili, B. Davari, and M. Vahedi, "Evaluation of bacterial and fungal contamination in the health care workers' hands and rings in the intensive care unit," Journal of Preventive Medicine and Hygiene, vol. 52, no. 4, pp. 215-218, 2011.

[3] L. J. Douglas, "Candida biofilms and their role in infection," Trends in Microbiology, vol. 11, no. 1, pp. 30-36, 2003.

[4] O. Gudlaugsson, S. Gillespie, K. Lee et al., "Attributable mortality of nosocomial candidemia, revisited," Clinical Infectious Diseases, vol. 37, no. 9, pp. 1172-1177, 2003.

[5] P. Afshar, S. Khodavaisy, S. Kalhori, M. Ghasemi, and T. Razavyoon, "Onychomycosis in North-East of Iran," Iranian Journal of Microbiology, vol. 6, no. 2, pp. 98-103, 2014.

[6] P. K. Mukherjee and J. Chandra, "Candida biofilm resistance," Drug Resistance Updates, vol. 7, no. 4-5, pp. 301-309, 2004.

[7] E. M. Kojic and R. O. Darouiche, "Candida infections of medical devices," Clinical Microbiology Reviews, vol. 17, no. 2, pp. 255267,2004

[8] M. Aliyali, M. Hedayati, M. Habibi, and S. Khodavaisy, "Clinical risk factors and bronchoscopic features of invasive aspergillosis in intensive care unit patients," Journal of Preventive Medicine and Hygiene, vol. 54, no. 2, pp. 80-82, 2013.

[9] G. S. Baillie and L. J. Douglas, "Matrix polymers of Candida biofilms and their possible role in biofilm resistance to antifungal agents," Journal of Antimicrobial Chemotherapy, vol. 46, no. 3, pp. 397-403, 2000.

[10] J. Chandra, P. K. Mukherjee, S. D. Leidich et al., "Antifungal resistance of Candidal biofilms formed on denture acrylic in vitro," Journal of Dental Research, vol. 80, no. 3, pp. 903-908, 2001.

[11] S. A. Yazdanparast, S. Khodavaisy, H. Fakhim et al., "Molecular characterization of highly susceptible Candida africana from vulvovaginal candidiasis," Mycopathologia, vol. 180, no. 5-6, pp. 317-323, 2015.
[12] N. Jain, R. Kohli, E. Cook, P. Gialanella, T. Chang, and B. C. Fries, "Biofilm formation by and antifungal susceptibility of Candida isolates from urine," Applied and Environmental Microbiology, vol. 73, no. 6, pp. 1697-1703, 2007.

[13] J.-L. Vincent, E. Anaissie, H. Bruining et al., "Epidemiology, diagnosis and treatment of systemic Candida infection in surgical patients under intensive care," Intensive Care Medicine, vol. 24, no. 3, pp. 206-216, 1998.

[14] H. Mirhendi, K. Makimura, M. Khoramizadeh, and H. Yamaguchi, "A one-enzyme PCR-RFLP assay for identification of six medically important Candida species," Nippon Ishinkin Gakkai Zasshi, vol. 47, no. 3, pp. 225-229, 2006.

[15] P. Wayne, "Reference method for broth dlution antifungal susceptibility testing of yeasts fungi," Approved Standard M38A2, 2008.

[16] S. Khodavaisy, M. Alialy, O. S. Mahdavi et al., "The study on fungal colonization of respiratory tract in patients admitted to intensive care units of sari and babol hospitals," Medical Journal of Mashhad University of Medical Sciences, vol. 54, no. 3, pp. 177184, 2011

[17] S. H. Fesharaki, I. Haghani, B. Mousavi, M. L. Kargar, M. Boroumand, and M. S. Anvari, "Endocarditis due to a coinfection of Candida albicans and Candida tropicalis in a drug abuser," Journal of Medical Microbiology, vol. 62, no. 11, pp. 17631767, 2013.

[18] I. Bitar, R. A. Khalaf, H. Harastani, and S. Tokajian, "Identification, typing, antifungal resistance profile, and biofilm formation of Candida albicans isolates from Lebanese hospital patients," BioMed Research International, vol. 2014, Article ID 931372, 10 pages, 2014.

[19] A. Bruder-Nascimento, C. H. Camargo, A. L. Mondelli, M. F. Sugizaki, T. Sadatsune, and E. Bagagli, "Candida species biofilm and Candida albicans ALS3 polymorphisms in clinical isolates," Brazilian Journal of Microbiology, vol. 45, no. 4, pp. 1371-1377, 2014.

[20] S. Silva, M. Henriques, A. Martins, R. Oliveira, D. Williams, and J. Azeredo, "Biofilms of non-Candida albicansCandida species: quantification, structure and matrix composition," Medical Mycology, vol. 47, no. 7, pp. 681-689, 2009.

[21] A. Z. Mahmoudabadi, M. Zarrin, and N. Kiasat, "Biofilm formation and susceptibility to amphotericin B and fluconazole in Candida albicans," Jundishapur Journal of Microbiology, vol. 7, no. 7, Article ID e17105, 2014.

[22] M. Laal Kargar, S. Fooladi-Rad, M. Mohammad Davoodi et al., "Fungal colonization in patients with cystic fibrosis," Journal of Mazandaran University of Medical Sciences, vol. 22, no. 2, pp. 204-218, 2013.

[23] P. Badiee and A. Alborzi, "Susceptibility of clinical Candida species isolates to antifungal agents by E-test, Southern Iran: a five year study," Iranian Journal of Microbiology, vol. 3, no. 4, pp. 183-188, 2011.

[24] N. Papon, V. Courdavault, M. Clastre, and R. J. Bennett, "Emerging and emerged pathogenic Candida species: beyond the Candida albicans paradigm," PLoS Pathogens, vol. 9, no. 9, Article ID e1003550, 2013.

[25] S. S. Richter, R. P. Galask, S. A. Messer, R. J. Hollis, D. J. Diekema, and M. A. Pfaller, "Antifungal susceptibilities of Candida species causing vulvovaginitis and epidemiology of recurrent cases," Journal of Clinical Microbiology, vol. 43, no. 5, pp. 2155-2162, 2005. 
[26] C. S. Aher, "Species distribution, virulence factors and antifungal susceptibility profile of Candida isolated from oropharyngeal lesions of HIV infected patients," International Journal of Current Microbiology and Applied Sciences, vol. 3, no. 1, pp. 453460, 2014.

[27] T. Shokohi, Z. Bandalizadeh, M. T. Hedayati, and S. Mayahi, "In vitro antifungal susceptibility of Candida species isolated from oropharyngeal lesions of patients with cancer to some antifungal agents," Jundishapur Journal of Microbiology, vol. 4, no. 2, pp. S19-S26, 2011.

[28] S. C. Deorukhkar and S. Saini, "Non albicans Candida species: its isolation pattern, species distribution, virulence factors and antifungal susceptibility profile," International Journal of Medical Science and Public Health, vol. 2, no. 3, pp. 533-538, 2013.

[29] S. C. Deorukhkar, S. Saini, and S. Mathew, "Non-albicans Candida infection: an emerging threat," Interdisciplinary Perspectives on Infectious Diseases, vol. 2014, Article ID 615958, 7 pages, 2014.

[30] M. Arendrup, E. Dzajic, R. Jensen et al., "Epidemiological changes with potential implication for antifungal prescription recommendations for fungaemia: data from a nationwide fungaemia surveillance programme," Clinical Microbiology and Infection, vol. 19, no. 8, pp. E343-E353, 2013.

[31] M. A. Pfaller, S. A. Messer, L. N. Woosley, R. N. Jones, and M. Castanheira, "Echinocandin and triazole antifungal susceptibility profiles for clinical opportunistic yeast and mold isolates collected from 2010 to 2011: application of new CLSI clinical breakpoints and epidemiological cutoff values for characterization of geographic and temporal trends of antifungal resistance," Journal of Clinical Microbiology, vol. 51, no. 8, pp. 2571-2581, 2013.

[32] L. Wiebusch, D. Lonchiati, L. Rodrigues, C. Dantas, A. Almeida, and K. Oliveira, "Profile susceptibility to fluconazole and voriconazole antifungals by species of Candida albicans isolated from urine culture," BMC Proceedings, vol. 8, supplement 4, article P34, 2014.

[33] A. L. Njunda, D. S. Nsagha, J. C. Assob, H. L. Kamga, and P. Teyim, "In vitro antifungal susceptibility patterns of Candida albicans from HIV and AIDS patients attending the Nylon Health District Hospital in Douala, Cameroon," Journal of Public Health in Africa, vol. 3, no. 1, p. 2, 2012.

[34] N. T. Wabe, J. Hussein, S. Suleman, and K. Abdella, "In vitro antifungal susceptibility of Candida albicans isolates from oral cavities of patients infected with human immunodeficiency virus in Ethiopia," Retrovirology, vol. 9, supplement 1, p. P44, 2012.

[35] R. C. Roy, G. D. Sharma, S. R. Barman, and S. Chanda, "Trend of Candida infection and antifungal resistance in a tertiary care hospital of north east India," Blood, vol. 100, p. 19, 2013.

[36] A. Al-Mamari, M. Al-Buryhi, M. A. Al-Heggami, and S. AlHag, "Identify and sensitivity to antifungal drugs of Candida species causing vaginitis isolated from vulvovaginal infected patients in Sana'a city," Der Pharma Chemica, vol. 6, no. 1, pp. 336-342, 2014.

[37] A. Awari, "Species distribution and antifungal susceptibility profile of Candida isolated from urine samples," International Journal of Applied and Basic Medical Research, vol. 18, pp. 228234, 2011.

[38] L. Zhang, S. Zhou, A. Pan, J. Li, and B. Liu, "Surveillance of antifungal susceptibilities in clinical isolates of Candida species at 36 hospitals in China from 2009 to 2013," International Journal of Infectious Diseases, vol. 33, pp. e1-e4, 2015.

[39] M. E. Bosco-Borgeat, C. G. Taverna, S. Cordoba et al., "Prevalence of candida dubliniensis fungemia in argentina: identification by a novel multiplex PCR and comparison of different phenotypic methods," Mycopathologia, vol. 172, no. 5, pp. 407414, 2011.

[40] P. Haddadi, S. Zareifar, P. Badiee et al., "Yeast colonization and drug susceptibility pattern in the pediatric patients with neutropenia," Jundishapur Journal of Microbiology, vol. 7, no. 9, Article ID el1858, 2014.

[41] S. Silva, M. Negri, M. Henriques, R. Oliveira, D. W. Williams, and J. Azeredo, "Candida glabrata, Candida parapsilosis and Candida tropicalis: biology, epidemiology, pathogenicity and antifungal resistance," FEMS Microbiology Reviews, vol. 36, no. 2, pp. 288-305, 2012.

[42] F. C. Bizerra, C. Jimenez-Ortigosa, A. C. R. Souza et al., "Breakthrough candidemia due to multidrug-resistant Candida glabrata during prophylaxis with a low dose of micafungin," Antimicrobial Agents and Chemotherapy, vol. 58, no. 4, pp. 2438-2440, 2014.

[43] L. X. Bonfietti, M. D. A. Martins, M. W. Szeszs et al., "Prevalence, distribution and antifungal susceptibility profiles of Candida parapsilosis, Candida orthopsilosis and Candida metapsilosis bloodstream isolates," Journal of Medical Microbiology, vol. 61, part 7, pp. 1003-1008, 2012.

[44] S. T. Tay, S. L. Na, and J. Chong, "Molecular differentiation and antifungal susceptibilities of Candida parapsilosis isolated from patients with bloodstream infections," Journal of Medical Microbiology, vol. 58, no. 2, pp. 185-191, 2009. 


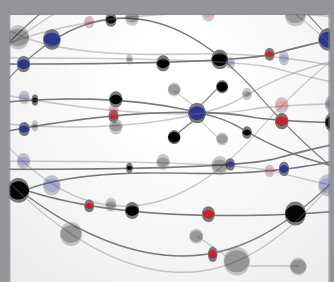

The Scientific World Journal
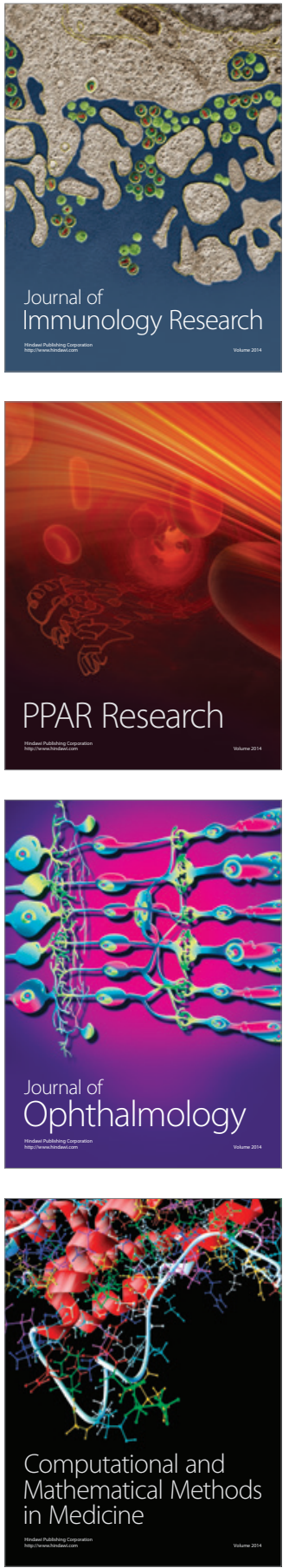

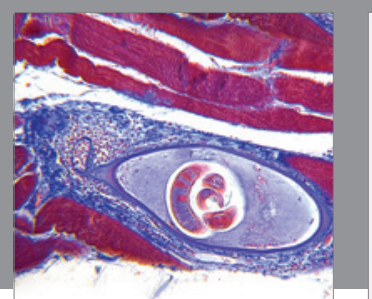

Gastroenterology Research and Practice

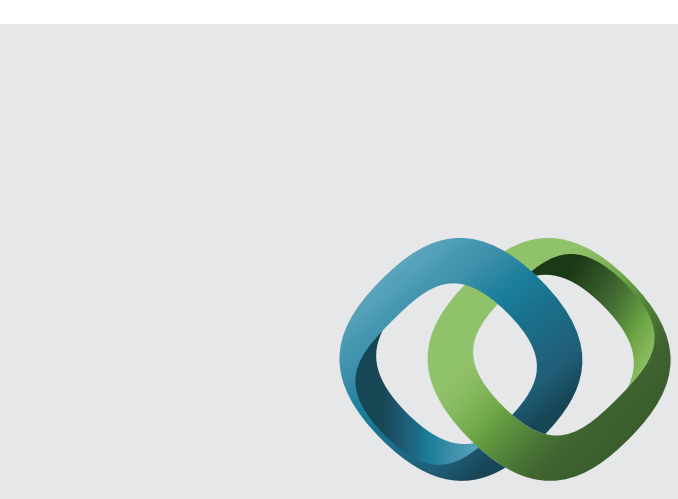

\section{Hindawi}

Submit your manuscripts at

http://www.hindawi.com
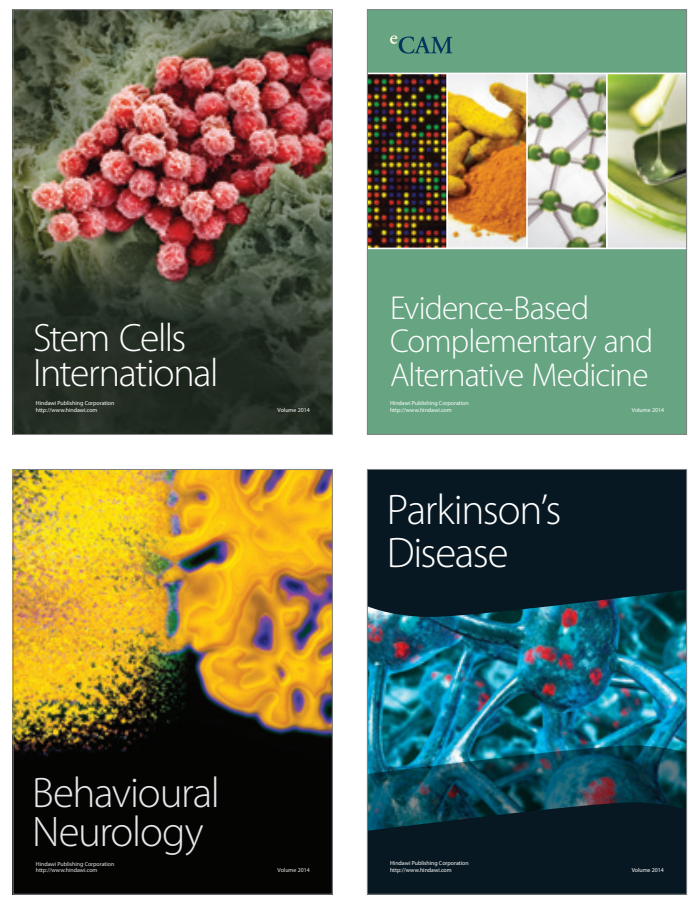
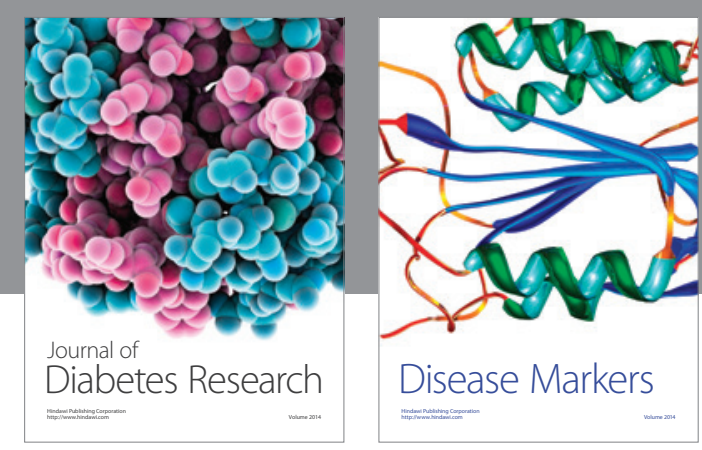

Disease Markers
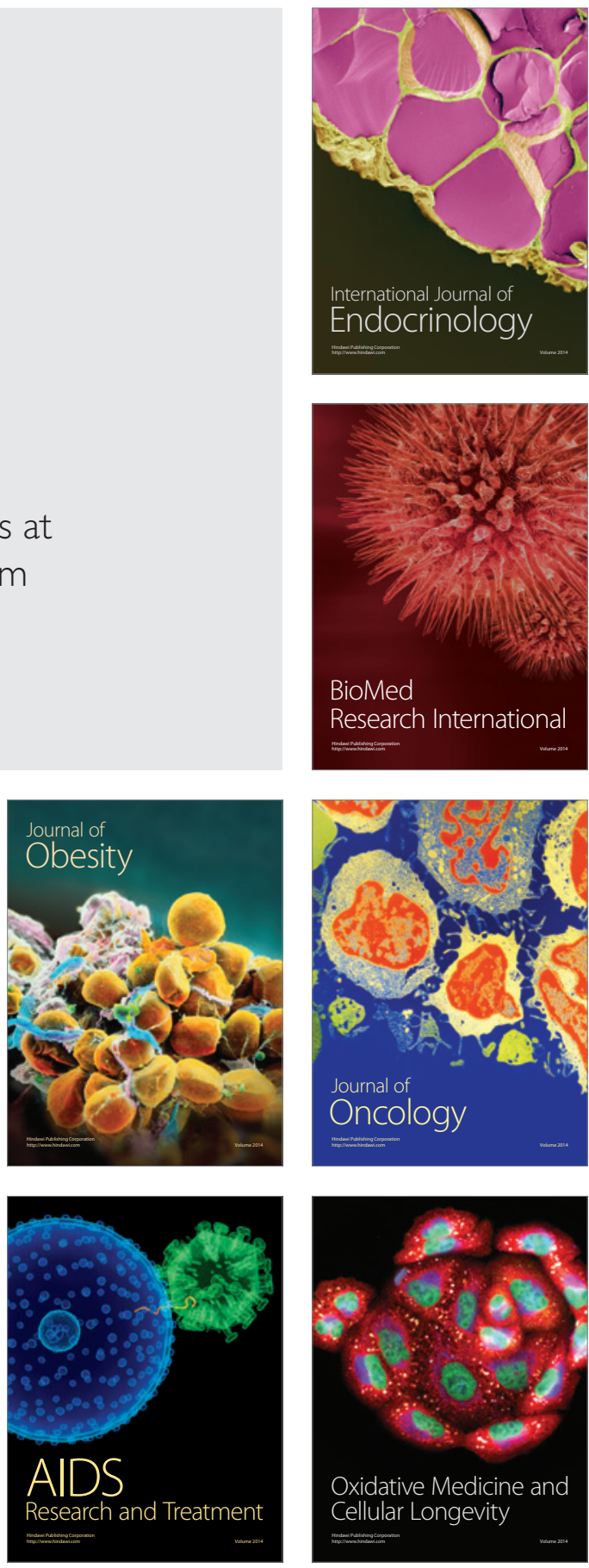